10

\title{
Особенности фотолюминесценции в кристаллах ниобата лития, легированных цинком в широком диапазоне концентраций
}

\author{
(C) Н.В. Сидоров ${ }^{1}$, М.В. Смирнов ${ }^{1 *}$, М.Н. Палатников ${ }^{1}$, В.Б. Пикулев ${ }^{2}$ \\ ${ }^{1}$ Институт химии и технологии редких элементов и минерального сырья им. И.В. Тананаева Федерального \\ исследовательского центра „Кольский научный центр Российской академии наук“, \\ 184209 Апатиты, Россия \\ 2 Петрозаводский государственный университет, \\ 185910 Петрозаводск, Россия \\ * e-mail: m.smirnov@ksc.ru
}

Поступила в редакцию 30.09.2020 г.

В окончательной редакции 15.01.2021 г.

Принята к публикации 15.01.2021 г.

Исследованы концентрационные изменения в спектрах фотолюминесценции кристаллов $\mathrm{LiNbO}_{3}: \mathrm{Zn}$ (0.004-6.5 mol.\% ZnO). Обнаружено, что с увеличением концентрации цинка от 0.004 до $1.42 \mathrm{~mol} . \% \mathrm{ZnO}$ наблюдается уменьшение интенсивности полос люминесценции, обусловленных дефектами $\mathrm{V}_{\mathrm{Li}}, \mathrm{Nb}_{\mathrm{Nb}}$, $\mathrm{Nb}_{\mathrm{Nb}}-\mathrm{Nb}_{\mathrm{Li}}$. С приближением состава кристалла ко второму концентрационному порогу $(\approx 7.0 \mathrm{~mol} . \% \mathrm{ZnO})$ происходит смещение люминесцентного гало на $\approx 0.41 \mathrm{eV}$ в высокоэнергетическую область спектра и увеличение интенсивности центров свечения с максимумами при 2.66 и $2.26 \mathrm{eV}$, обусловленными возможным появлением точечных дефектов $\mathrm{Zn}_{\mathrm{Li}}$. Показано, что в кристалле $\mathrm{LiNbO}_{3}: \mathrm{Zn}(4.69 \mathrm{~mol} \% \mathrm{ZnO})$, полученном по технологии гомогенного легирования, существует большее количество центров свечения разной природы, чем в конгруэнтном и в легированных цинком кристаллах, полученных по технологии прямого легирования расплава. В кристалле $\mathrm{LiNbO}_{3}: \mathrm{Zn}(4.52 \mathrm{~mol} \% \mathrm{ZnO})$ наблюдается тушение люминесценции основных дефектов $\left(\mathrm{V}_{\mathrm{Li}}, \mathrm{Nb}_{\mathrm{Nb}}, \mathrm{Zn}_{\mathrm{Li}}\right)$ за счет увеличения доли безызлучательных переходов относительно других кристаллов $\mathrm{LiNbO}_{3}: \mathrm{Zn}$ в диапазоне концентрации $[\mathrm{ZnO}]=4.46-6.50 \mathrm{~mol} . \%$.

Ключевые слова: монокристалл ниобат лития, прямое и гомогенное легирование, фотолюминесценция, центры свечения, дефекты.

DOI: $10.21883 /$ OS.2021.05.50891.248-20

\section{Введение}

Использование нелинейно-оптического кристалла ниобата лития $\left(\mathrm{LiNbO}_{3}\right)$ как функционального материала нелинейной, поляризационной и интегральной оптики, лазерной техники и оптоэлектроники во многом определяется его структурными дефектами и люминесцентными свойствами. $\mathrm{LiNbO}_{3}$ - сегнетоэлектрик с кислородно-октаэдрической структурой, c широкой областью гомогенности на фазовой диаграмме, c запрещенной зоной, существенно зависящей от состава, близкой по величине к широкозонным полупроводникам [1-7]. В кристалле $\mathrm{LiNbO}_{3}$ существует сильная зависимость тонких особенностей структуры и многих физических свойств, определяемых точечными дефектами, от вида и концентрации нефоторефрактивной легирующей добавки. Путем легирования можно эффективно воздействовать на состояние ансамбля дефектов в структуре и регулировать, тем самым, люминесцентные и многие другие свойства кристалла. Воздействие легирующих нефоторефрактивных катионов $\mathrm{Zn}^{2+}, \mathrm{Mg}^{2+}$, $\mathrm{Er}^{3+}$ и др. на оптические свойства и композиционную однородность кристалла $\mathrm{LiNbO}_{3}$ сводится в основном к „регулированию“ содержания в кристалле многочисленных точечных дефектов в виде неправильно расположенных вдоль полярной оси основных $\left(\mathrm{Li}^{+}\right.$и $\mathrm{Nb}^{5+}$ ) и примесных катионов, а также вакансий [1-7]. Основными точечными дефектами в номинально чистом кристалле конгруэнтного состава $(R=\mathrm{Li} / \mathrm{Nb}=0.946)$ являются дефекты $\mathrm{Nb}_{\mathrm{Li}}$ (катионы $\mathrm{Nb}^{5+}$, расположенные в позициях катионов $\mathrm{Li}^{+}$идеальной структуры стехиометрического состава, $R=1$ ), являющиеся наиболее глубокими электронными ловушками $[2,4-6]$. Легирование конгруэнтного кристалла нефоторефрактивными катионами приводит к изменению поляризуемости кислородно-октаэдрических кластеров $\mathrm{MeO}_{6}(\mathrm{Me}-$ $\mathrm{Li}^{+}, \mathrm{Nb}^{5+}$, легирующий катион, вакансия) и параметров кристаллической решетки [4-6]. Оно оказывает существенное влияние на колебательный спектр, край фундаментального оптического поглощения, фоторефрактивные и люминесцентные характеристики кристалла [1,4-7]. Вхождение нефоторефрактивных катионов $\mathrm{Mg}^{2+}, \mathrm{Zn}^{2+} \mathrm{Er}^{3+}$ и др. в структуру кристалла имеет скачкообразный (пороговый) характер [5].

Если кристаллы $\mathrm{LiNbO}_{3}$, легированные магнием $\left(\mathrm{LiNbO}_{3}: \mathrm{Mg}\right)$, уже нашли широкое применение для преобразования и модуляции лазерного излучения [8], то кристаллы, легированные цинком $\left(\mathrm{LiNbO}_{3}: \mathrm{Zn}\right)$, до сих пор не нашли коммерческого использования. Между тем кристаллы $\mathrm{LiNbO}_{3}: \mathrm{Zn}$ композиционно более однородны, 
чем кристаллы $\mathrm{LiNbO}_{3}: \mathrm{Mg}$, обладают низким значением напряженности коэрцитивного поля $(2.7-3.5 \mathrm{kV} / \mathrm{mm})$ и эффекта фоторефракции [4-7], что важно для создания материалов для преобразования частот лазерного излучения в режиме фазового квазисинхроизма на периодически поляризованных доменных структурах микронных и субмикронных размеров, формируемых в кристалле [9]. При этом существенным технологическим преимуществом кристаллов $\mathrm{LiNbO}_{3}: \mathrm{Zn}$ является то, что при изменении концентрации цинка в кристалле происходит более плавное изменение состояния дефектности и физических характеристик кристалла, чем при изменении концентрации магния. Мешающими факторами для преобразования лазерного излучения кристаллом $\mathrm{LiNbO}_{3}$ являются эффект фоторефракции и фотолюминесценция, которая в отличие от эффекта фоторефракции в кристаллах $\mathrm{LiNbO}_{3}: \mathrm{Zn}$ практически не исследовалась.

Исследование фотолюминесценции кристаллов $\mathrm{LiNbO}_{3}$, легированных цинком в широком диапазоне концентраций, включающем концентрационные пороги, даст важную информацию о центрах свечения и перераспределении поглощенной энергии между данными центрами при изменении концентрации цинка, позволит определить составы, обладающие наименьшей излучательной рекомбинацией в видимой области спектра, что является важным для создания функциональных материалов для генерации второй гармоники лазерного излучения в видимой области спектра.

В настоящей работе исследованы люминесцентные свойства с объема кристаллов $\mathrm{LiNbO}_{3}: \mathrm{Zn}$ (0.004-6.50 mol.\% ZnO) различного генезиса. Для сравнения использовался номинально чистый кристалл $\mathrm{LiNbO}_{3}$, выращенный из конгруэнтного расплава $(\mathrm{Li} / \mathrm{Nb}=0.946)$.

\section{Методика эксперимента}

Все кристаллы $\mathrm{LiNbO}_{3}$ были выращены в воздушной атмосфере методом Чохральского на установке „Кристалл $2^{“}$. Использовалась шихта метаниобата лития, разработанная в ИХТРЭМС КНЦ РАН [10]. Кристаллы с концентрацией $0.004,0.07,1.19,1.42,2.00,4.46,4.52$, 5.50 и $6.50 \mathrm{~mol} \% \mathrm{ZnO}$ получены с использованием метода прямого легирования расплава: перед наплавлением тигля оксид цинка смешивали непосредственно с шихтой ниобата лития конгруэнтного состава. Кристалл $\mathrm{LiNbO}_{3}: \mathrm{Zn}$ (4.69 mol.\% ZnO) был выращен из шихты, синтезированной с использованием прекурсора $\mathrm{Nb}_{2} \mathrm{O}_{5}: \mathrm{Zn}$ по технологии, описанной в работе [11]. При выращивании кристаллов $\mathrm{LiNbO}_{3}: \mathrm{Zn}$ перед затравливанием с целью гомогенизации расплава производится его перегрев (на $150-200^{\circ} \mathrm{C}$ ) относительно температуры плавления ниобата лития с выдержкой в течении 4-6h [7]. Концентрация следовых количеств неконтролируемых примесей $(\mathrm{Mn}, \mathrm{V}, \mathrm{Mg}, \mathrm{Sn}, \mathrm{Cu}, \mathrm{Pb}, \mathrm{Ni}, \mathrm{Cr}, \mathrm{Co}$, $\mathrm{Mo}, \mathrm{Si}, \mathrm{Fe}, \mathrm{Ti}, \mathrm{Al}, \mathrm{Ca})$ в исследованных кристаллах не превышала $10^{-4}-10^{-3}$ wt.\%.

Монодоменизация кристаллов осуществлялась методом высокотемпературного электродиффузионного отжига при охлаждении образцов со скоростью $20^{\circ} \mathrm{C} / \mathrm{h}$ в температурном интервале от $\sim 1240-890^{\circ} \mathrm{C}$ в условиях приложения электрического напряжения [11]. Контроль степени монодоменности осуществлялся методом импедансной спектроскопии и измерения величины статического пьезомодуля $\left(d_{333 \mathrm{st}}\right)$ кристаллической були. Исследуемые образцы, вырезанные из кристаллической були, представляли собой прямоугольные параллелепипеды с размерами $\sim 8 \times 7 \times 6 \mathrm{~mm}$, ребра которых совпадали с направлениями кристаллографических осей $X, Y, Z$ $(Z-$ полярная ось кристалла). Грани параллелепипедов тщательно полировались.

Измерение спектров фотолюминесценции проводилось с помощью спектрографа SOL SL-100M с ПЗС-детектором FLI ML 1107 Black Illuminated (Hamamatsu) в диапазоне длин волн $380-750 \mathrm{~nm} \mathrm{в}$ нормальных условиях. ПЗС-матрица в рабочем режиме охлаждалась элементом Пельтье до $-30^{\circ} \mathrm{C}$. Ширина входной щели монохроматора составляла $1.00 \mathrm{~mm}$. Максимальное значение люминесцентного сигнала нормировано на максимум чувствительности ПЗС-матрицы. В качестве источника возбуждения люминесценции использовался непрерывный $\mathrm{He}-\mathrm{Cd}$-лазер $(325 \mathrm{~nm}, 15 \mathrm{~mW})$. Спектры регистрировались в трех разных точках объема каждого исследуемого образца с последующим усреднением по интенсивности. Все спектры раскладывались на ряд индивидуальных полос люминесценции с помощью программы разделения контуров. Точность определения положений, ширин и интенсивностей индивидуальных полос свечения составляла $\pm 0.004,0.006 \mathrm{eV}$ и $5 \%$ соответственно.

\section{Результаты и их обсуждение}

На рис. $1, a, b$ представлены концентрационные изменения в спектрах фотолюминесценции двух серий кристаллов $\mathrm{LiNbO}_{3}: \mathrm{Zn}(0.004-2.00 \mathrm{~mol} . \% \mathrm{ZnO})$ и $\mathrm{LiNbO}_{3}: \mathrm{Zn}(4.46-6.50 \mathrm{~mol} . \% \mathrm{ZnO})$, происходящие при приближении состава кристалла соответственно к первому $(\approx 3.0 \mathrm{~mol} . \% \mathrm{ZnO})$ и ко второму $(\approx 7.0 \mathrm{~mol} . \% \mathrm{ZnO})$ концентрационным порогам. Там же для сравнения приведен спектр номинально чистого кристалла $\mathrm{LiNbO}_{3}$. Все спектры получены с объема кристалла. Основные параметры полос люминесценции $\left(I_{m}-\right.$ интенсивность люминесценции в максимуме; $w$ - полуширина пика на половине высоты; $E$ - положение максимума пика люминесценции) представлены в таблице. На рис. 2 представлены зависимости $I_{m}$ полос излучения при 1.99 , $2.26,2.50,2.66$ и $3.19 \mathrm{eV}$ от концентрации цинка в исследуемых кристаллах $\mathrm{LiNbO}_{3}$. 

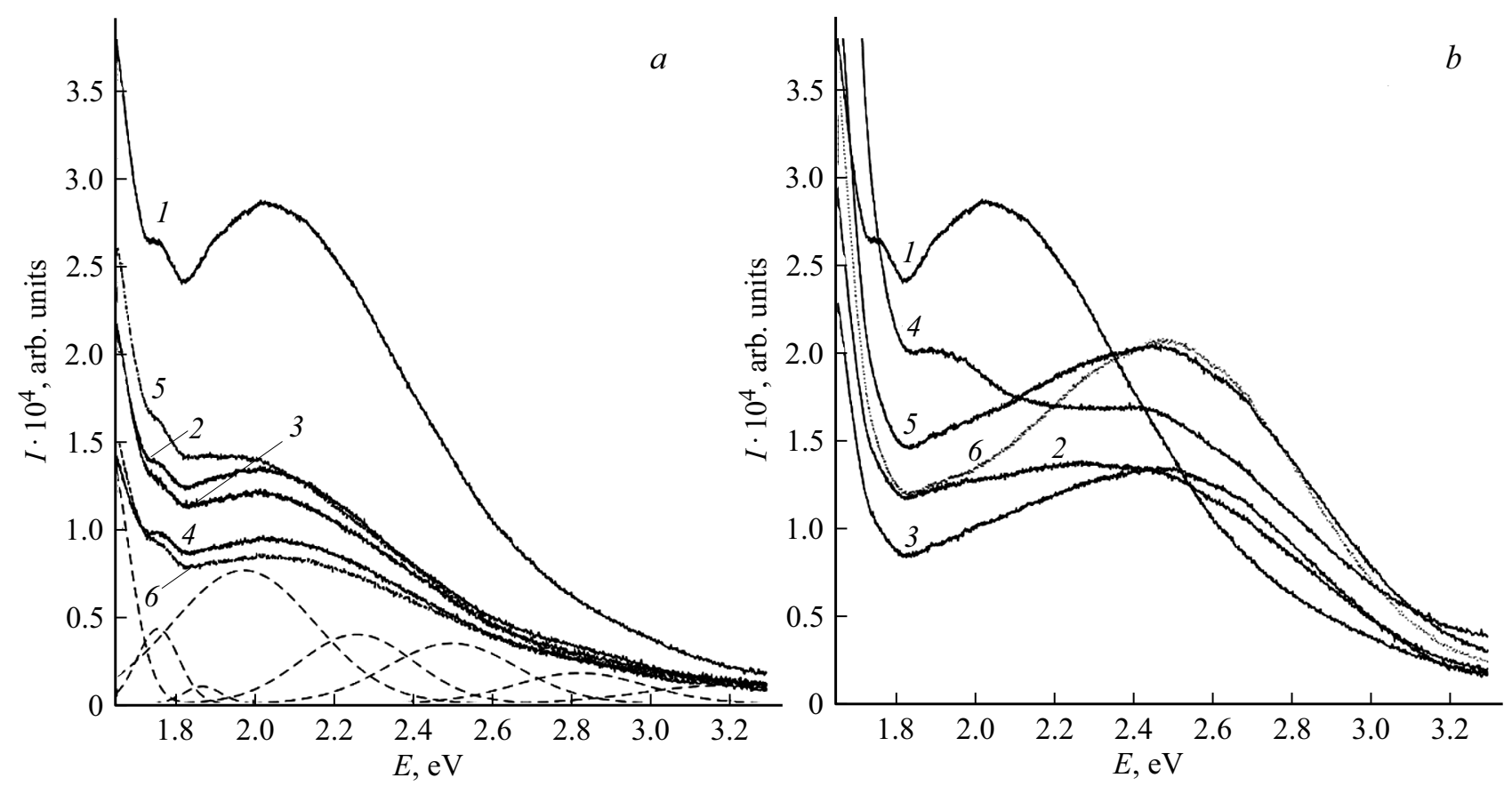

Рис. 1. Спектры фотолюминесценции кристаллов $\mathrm{LiNbO}_{3}: \mathrm{Zn}$ вблизи концентрационных порогов при $\approx 3.0$ (a) и при $\approx 7.0$ (b) mol.\% $\mathrm{ZnO}:$ (a) $1-0$ (конгруэнтный $\mathrm{LiNbO}_{3}$ ), $2-0.004,3-0.07,4-1.19,5-1.42,6-2.00 \mathrm{~mol} . \% \mathrm{ZnO}$. (b) $1-0$ (конгруэнтный $\mathrm{LiNbO}_{3}$ ), $2-4.46,3-4.52,4-4.69,5-5.50,6-6.50 \mathrm{~mol} \% \mathrm{ZnO}$.

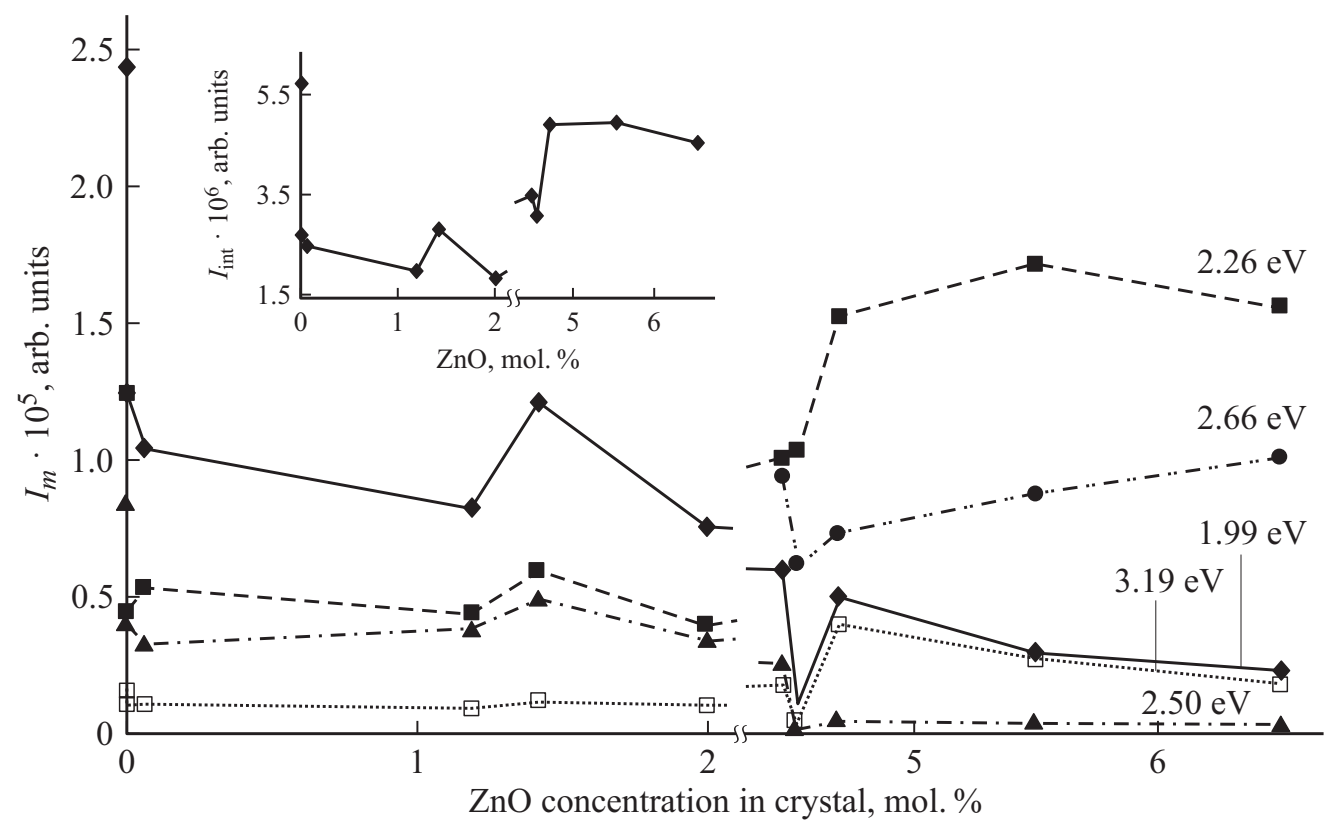

Рис. 2. Зависимость интенсивности $I_{m}$ полос излучения при $1.99,2.26,2.50,2.66$ и $3.19 \mathrm{eV}$ от концентрации $\mathrm{Zn}$ в кристалле $\mathrm{LiNbO}_{3}$. На вставке представлена зависимость интегральной интенсивности люминесцентного гало от концентрации $\mathrm{Zn}$ в кристалле $\mathrm{LiNbO}_{3}$.

Диапазон концентраций 0.004-2.00 mol.\% ZnO вблизи первого концентрационного порога интересен тем, что внутри него обнаружена достаточно широкая (0.05-1.12 mol.\% ZnO) область максимального упорядочения структурных единиц кристалла $\mathrm{LiNbO}_{3}: \mathrm{Zn}$ [11]. В области 0.05-1.12 mol.\% $\mathrm{ZnO}$ концентрационные за- висимости ширин линий в спектре комбинационного рассеяния света (КРС), соответствующих $A_{1}(\mathrm{TO})$ фундаментальным колебаниям внутриоктаэдрических ионов $\mathrm{Nb}^{5+}$ и $\mathrm{Li}^{+}$вдоль полярной оси и ионов кислорода октаэдров $\mathrm{O}_{6}$, испытывают минимум. Этот факт свидетельствует о повышении упорядочения структурных 
Характеристики и отнесение полос люминесценции в спектрах кристаллов после разложения спектров на составляющие

\begin{tabular}{|c|c|c|c|c|c|c|c|c|}
\hline \multicolumn{2}{|c|}{ Отнесение полосы } & $\mathrm{V}_{\mathrm{Nb}}$ & $\mathrm{Nb}_{\mathrm{Nb}}$ & $\mathrm{Zn}_{\mathrm{Li}}$ & $\mathrm{V}_{\mathrm{Li}}$ & $\mathrm{Nb}_{\mathrm{Li}}$ & $\mathrm{Nb}_{\mathrm{Nb}}-\mathrm{Nb}_{\mathrm{Li}}$ & $?^{*}$ \\
\hline \multirow{3}{*}{$\begin{array}{c}\text { конгруэнтный } \\
\mathrm{LiNbO}_{3}\end{array}$} & $I_{m}$, arb. uniits & 1590 & 3481 & - & 8472 & 12361 & 24354 & 6451 \\
\hline & $w, \mathrm{eV}$ & 0.673 & 0.456 & - & 0.414 & 0.369 & 0.417 & 0.094 \\
\hline & $E, \mathrm{eV}$ & 3.189 & 2.818 & - & 2.501 & 2.262 & 1.990 & 1.763 \\
\hline \multirow{3}{*}{$\begin{array}{c}\mathrm{LiNbO}_{3}: \mathrm{Zn} \\
(0.004 \text { mol.\% } \mathrm{ZnO})\end{array}$} & $I_{m}$, arb. units & 993 & 2792 & - & 4031 & 4456 & 12450 & 4010 \\
\hline & $w, \mathrm{eV}$ & 0.489 & 0.429 & - & 0.339 & 0.314 & 0.453 & 0.110 \\
\hline & $E, \mathrm{eV}$ & 3.227 & 2.796 & - & 2.493 & 2.277 & 2.000 & 1.761 \\
\hline \multirow{3}{*}{$\begin{array}{c}\mathrm{LiNbO}_{3}: \mathrm{Zn} \\
(0.07 \mathrm{~mol} . \% \mathrm{ZnO})\end{array}$} & $I_{m}$, arb. units & 1101 & 1540 & - & 3281 & 5312 & 10420 & 6979 \\
\hline & $w, \mathrm{eV}$ & 0.586 & 0.433 & - & 0.464 & 0.393 & 0.420 & 0.149 \\
\hline & $E, \mathrm{eV}$ & 3.181 & 2.819 & - & 2.499 & 2.272 & 1.979 & 1.745 \\
\hline \multirow{3}{*}{$\begin{array}{c}\mathrm{LiNbO}_{3}: \mathrm{Zn} \\
(1.19 \mathrm{~mol} . \% \mathrm{ZnO})\end{array}$} & $I_{m}$, arb. units & 906 & 2048 & - & 3845 & 4324 & 8250 & 2235 \\
\hline & $w, \mathrm{eV}$ & 0.365 & 0.370 & - & 0.373 & 0.333 & 0.401 & 0.089 \\
\hline & $E, \mathrm{eV}$ & 3.180 & 2.820 & - & 2.480 & 2.244 & 1.979 & 1.772 \\
\hline \multirow{3}{*}{$\begin{array}{c}\mathrm{LiNbO}_{3}: \mathrm{Zn} \\
(1.42 \mathrm{~mol} . \% \mathrm{ZnO})\end{array}$} & $I_{m}$, arb. units & 1201 & 1498 & - & 4936 & 5927 & 12111 & 6398 \\
\hline & $w, \mathrm{eV}$ & 0.565 & 0.360 & - & 0.405 & 0.338 & 0.370 & 0.122 \\
\hline & $E, \mathrm{eV}$ & 3.180 & 2.835 & - & 2.473 & 2.231 & 1.968 & 1.761 \\
\hline \multirow{3}{*}{$\begin{array}{c}\mathrm{LiNbO}_{3}: \mathrm{Zn} \\
(2.00 \mathrm{~mol} . \% \mathrm{ZnO})\end{array}$} & $I_{m}$, arb. units & 1021 & 1726 & - & 3414 & 3922 & 7565 & 4237 \\
\hline & $w, \mathrm{eV}$ & 0.477 & 0.384 & - & 0.387 & 0.338 & 0.421 & 0.123 \\
\hline & $E, \mathrm{eV}$ & 3.180 & 2.820 & - & 2.498 & 2.259 & 1.974 & 1.759 \\
\hline \multirow{3}{*}{$\begin{array}{c}\mathrm{LiNbO}_{3}: \mathrm{Zn} \\
(4.46 \mathrm{~mol} . \% \mathrm{ZnO})\end{array}$} & $I_{m}$, arb. units & 1718 & - & 9362 & 2596 & 10097 & 5978 & 5497 \\
\hline & $w, \mathrm{eV}$ & 0.479 & - & 0.551 & 0.271 & 0.401 & 0.352 & 0.173 \\
\hline & $E, \mathrm{eV}$ & 3.145 & - & 2.659 & 2.475 & 2.229 & 1.975 & 1.749 \\
\hline \multirow{3}{*}{$\begin{array}{c}\mathrm{LiNbO}_{3}: \mathrm{Zn} \\
(4.52 \mathrm{~mol} \% \% \mathrm{ZnO})\end{array}$} & $I_{m}$, arb. units & 522 & - & 6185 & 205 & 10352 & 1109 & 2263 \\
\hline & $w, \mathrm{eV}$ & 0.538 & - & 0.653 & 0.102 & 0.879 & 0.225 & 0.090 \\
\hline & $E, \mathrm{eV}$ & 3.22 & - & 2.678 & 2.496 & 2.232 & 1.976 & 1.762 \\
\hline \multirow{3}{*}{$\begin{array}{c}\mathrm{LiNbO}_{3}: \mathrm{Zn} \\
(4.69 \mathrm{~mol} . \% \mathrm{ZnO})\end{array}$} & $I_{m}$, arb. units & 3992 & - & 7304 & 502 & 15252 & 4982 & 6199 \\
\hline & $w, \mathrm{eV}$ & 0.648 & - & 0.528 & 0.146 & 0.722 & 0.258 & 0.148 \\
\hline & $E, \mathrm{eV}$ & 3.091 & - & 2.661 & 2.448 & 2.206 & 1.978 & 1.763 \\
\hline \multirow{3}{*}{$\begin{array}{c}\mathrm{LiNbO}_{3}: \mathrm{Zn} \\
(5.50 \mathrm{~mol} . \% \mathrm{ZnO})\end{array}$} & $I_{m}$, arb. units & 2750 & - & 8739 & 441 & 17178 & 2946 & 4770 \\
\hline & $w, \mathrm{eV}$ & 0.791 & - & 0.566 & 0.147 & 0.772 & 0.268 & 0.101 \\
\hline & $E, \mathrm{eV}$ & 3.100 & - & 2.688 & 2.480 & 2.243 & 1.945 & 1.763 \\
\hline \multirow{3}{*}{$\begin{array}{c}\mathrm{LiNbO}_{3}: \mathrm{Zn} \\
(6.50 \mathrm{~mol} . \% \mathrm{ZnO})\end{array}$} & $I_{m}$, arb. units & 1815 & - & 10098 & 376 & 15582 & 2284 & 4108 \\
\hline & $w, \mathrm{eV}$ & 0.606 & - & 0.583 & 0.125 & 0.768 & 0.213 & 0.098 \\
\hline & $E, \mathrm{eV}$ & 3.171 & - & 2.670 & 2.488 & 2.268 & 1.939 & 1.767 \\
\hline
\end{tabular}

Примечание. ${ }^{*}$ Неизвестный центр свечения.

единиц катионной подрешетки вдоль полярной оси. При этом кислородно-октаэдрические кластеры $\mathrm{MeO}_{6}(\mathrm{Me}-$ основные, $\mathrm{Li}^{+}, \mathrm{Nb}^{5+}$ - примесные катионы или вакан- сии), ответственные за нелинейно-оптические, сегнетоэлектрические и люминесцентные свойства кристалла, деформируются так, что кислородные октаэдры $\mathrm{O}_{6}$ ста- 
новятся более совершенными [11]. В области максимального упорядочения структурных единиц кристалла $\mathrm{LiNbO}_{3}: \mathrm{Zn}$ наблюдается минимум в концентрационной зависимости параметра $c$ элементарной ячейки [5], т.е. происходит „сжатие“ структуры вдоль полярной оси. В то время как параметр $c$ должен увеличиваться, поскольку ионный радиус цинка $(0.74 \AA)$ больше ионных радиусов лития $(0.68 \AA)$ и ниобия $(0.68 \AA)$. Интересно отметить и то, что коэффициенты линейного электрооптического эффекта в кристаллах $\mathrm{LiNbO}_{3}: \mathrm{Zn}$ разного состава меньше, чем в конгруэнтном кристалле $\mathrm{LiNbO}_{3}$, и в их концентрационном поведении также наблюдается минимум при концентрации $\approx 2-3 \mathrm{~mol} \% \mathrm{ZnO}$ и максимум в области второго концентрационного порога при $\approx 7 \mathrm{~mol} . \% \mathrm{ZnO}$, где структура кристалла существенно разупорядочена $[4,5]$. Кроме того, при концентрациях до $3.0 \mathrm{~mol} . \% \mathrm{ZnO}$ происходит наибольшее подавление эффекта фоторефракции в кристалле $\mathrm{LiNbO}_{3}: \mathrm{Zn}$ [5]. В области концентраций 0-3.0 mol.\% $\mathrm{ZnO}$ эффект фоторефракции уменьшается с $3.1 \cdot 10^{2}$ до $6.6 \cdot 10^{2} \mathrm{~W} / \mathrm{cm}^{2}$, a в области концентраций $5-7 \mathrm{~mol} \% \mathrm{ZnO}-\mathrm{c} 7.1 \cdot 10^{2}$ до $9.8 \cdot 10^{2} \mathrm{~W} / \mathrm{cm}^{2}$ [5]. Приведенные данные свидетельствуют о существенной перестройке подрешетки дефектов (вторичной структуры) с изменением концентрации ионов $\mathrm{Zn}^{2+}$ в кристалле $\mathrm{LiNbO}_{3}$, которые неизбежно должны проявиться в спектрах фотолюминесценции.

Из рис. 1, a видно, что экспериментально наблюдаемые спектры фотолюминесценции конгруэнтного кристалла $\mathrm{LiNbO}_{3}$ и серии кристаллов $\mathrm{LiNbO}_{3}: \mathrm{Zn}$ (0.004-2.00 mol.\% ZnO) состоят из двух широких сложных полос с главными максимумами при $\approx 2.05$ и $\approx 1.75 \mathrm{eV}$. Анализ полосы с основным максимумом при $\approx 2.05 \mathrm{eV}$ по программе разделения контуров показывает, что она состоит по крайне мере из 5 элементарных полос излучения гауссовой формы (таблица, рис. $1, a$ ). Интегральная интенсивность и положение максимумов элементарных полос различны для кристаллов разного состава. Разложение сложной полосы с максимумом при $\approx 2.05 \mathrm{eV}$ на составляющие проводилось на основании литературных данных о полосах фотолюминесценции в кристалле $\mathrm{LiNbO}_{3}$ в видимой области спектра [12-16]. При этом для лучшей аппроксимации профиля сложного реального контура вводились дополнительные элементарные полосы с максимумами при $1.91 \mathrm{eV}$ и максимума в ближней ИК области спектра. Коэффициент детерминации $\left(R^{2}\right)$ использовался в качестве критерия соответствия экспериментального и теоретического спектров. Для всех исследуемых спектров его значение в среднем составляло 0.9992.

Из рис. 1, $a$ и таблицы видно, что интегральная интенсивность всех элементарных полос люминесценции с максимумами при $3.19,2.82,2.50,2.26,1.99$ и $1.76 \mathrm{eV}$ в спектре кристаллов $\mathrm{LiNbO}_{3}: \mathrm{Zn}(0.004-2.00 \mathrm{~mol} . \% \mathrm{ZnO})$ существенно меньше, чем в спектре конгруэнтного кристалла $\mathrm{LiNbO}_{3}$. Увеличение концентрации $\mathrm{Zn}$ до 1.19 mol.\% ZnO (т.е. в пределах области максимального упорядочения кристалла $\left.\mathrm{LiNbO}_{3}: \mathrm{ZnO}\right)$ приводит к уменьшению интегральной интенсивности люминесцентного гало и элементарных полос с максимумами при 2.26 и $1.99 \mathrm{eV}$ (таблица, вставка на рис. 2), что свидетельствует об уменьшении концентрации дефектов, ответственных за соответствующие процессы излучательной рекомбинации. При концентрации $1.42 \mathrm{~mol} \% \mathrm{ZnO}$ в кристалле происходит увеличение интегральной интенсивности всех полос люминесценции. Однако при концентрации $2.00 \mathrm{~mol}$ \% вновь наблюдается минимальная интенсивность свечения (таблица, рис. 2). Необходимо отметить и то, что для всех образцов наблюдается подъем интенсивности фотолюминесценции в ближней ИК области спектра $(\lambda>750 \mathrm{~nm})$ с увеличением концентрации цинка в кристалле.

Каждый отдельный спектр люминесценции (таблица, рис. 1), выделенный путем разложения сложной полосы на составлявшие с максимумом при $\approx 2.05 \mathrm{eV}$, соответствует определенным центрам свечения, природа которых обусловлена излучательной рекомбинацией в кристалле дефектов определенного типа. При этом в связи с малым содержанием $\left(<10^{-3} \mathrm{wt} . \%\right)$ в кристалле $\mathrm{LiNbO}_{3}$ точечных дефектов в виде следовых количеств многочисленных примесных катионов металлов [7] и их статистическим распределением в кристалле по кислородным октаэдрам проявление таких дефектов в общем спектре люминесценции происходит в виде „шума“, „размазанного“ по всему спектральному диапазону. Этим „шумом“ можно пренебречь при интерпретации спектров. Все остальные полосы в спектре люминесценции исследованных кристаллов $\mathrm{LiNbO}_{3}$ можно интерпретировать следующим образом. Согласно литературным данным [13], в спектре фотолюминесценции конгруэнтного кристалла $\mathrm{LiNbO}_{3}$ полоса с максимумом при $2.38 \mathrm{eV}$ обусловлена дефектами $\mathrm{Nb}_{\mathrm{Li}}$. В спектрах исследованных нами кристаллов наиболее близкими к данной полосе являются полосы с максимумами при 2.50 и $2.26 \mathrm{eV}$ (таблица, рис. 1). На основании данных по катодолюминесценции авторы работы [16] предполагают, что максимумы при 2.5 и $3.3 \mathrm{eV}$ обусловлены дефектами $\mathrm{V}_{\mathrm{Li}}$ и $\mathrm{V}_{\mathrm{Nb}}$, находящимися в основных ниобиевом и литиевом мотивах. В работе [15] на основании квантовомеханических расчетов в кристалле $\mathrm{LiNbO}_{3}$ оптических переходов для дефектов в виде биполярона $\mathrm{Nb}_{\mathrm{Nb}}^{4+}-\mathrm{Nb}_{\mathrm{Li}}^{4+}$ показано, что часть рассчитанных значений переходов лежит в видимой области спектра при 2.0 и $2.3 \mathrm{eV}$. В конгруэнтном кристалле $\mathrm{LiNbO}_{3}$ на один дефект $\mathrm{Nb}_{\mathrm{Li}}$ приходится четыре дефекта $\mathrm{V}_{\mathrm{Li}}$ [5]. Следовательно, количество пар $\mathrm{Nb}_{\mathrm{Nb}}-\mathrm{Nb}_{\mathrm{Li}}$ преобладает в кристалле над другими дефектами, поэтому пары $\mathrm{Nb}_{\mathrm{Nb}}-\mathrm{Nb}_{\mathrm{Li}}$ вносят наибольший вклад в люминесцентный сигнал в видимой области спектра. На основании вышеизложенного полосы излучения в спектрах исследованных нами кристаллов $\mathrm{LiNbO}_{3}$ с максимумами при 3.19, 2.50, 2.26 и $1.99 \mathrm{eV}$ следует соответственно отнести к излучательной рекомбинации с участием точечных дефектов $\mathrm{V}_{\mathrm{Nb}}, \mathrm{V}_{\mathrm{Li}}$, $\mathrm{Nb}_{\mathrm{Li}}$ и пар $\mathrm{Nb}_{\mathrm{Nb}}-\mathrm{Nb}_{\mathrm{Li}}$. Полоса люминесценции при $2.82 \mathrm{eV}$ соответствует паре $\mathrm{Nb}^{4+}-\mathrm{O}^{-}$, при этом ион 
$\mathrm{Nb}^{5+}$ находится в основной позиции [13]. Уместно отметить, что данный центр свечения доминирует в спектрах люминесценции от приповерхностного слоя кристалла $\mathrm{LiNbO}_{3}$ и в спектрах керамических твердых растворов на основе ниобатов-танталатов щелочных и редкоземельных металлов [17,18]. Для корректного разложения спектров кристаллов $\mathrm{LiNbO}_{3}: \mathrm{Zn}(4.46-6.50 \mathrm{~mol} . \% \mathrm{ZnO})$ на составляющие совместно с ранее упомянутыми максимумами пришлось ввести дополнительный пик при $2.66 \mathrm{eV}$, который не проявлялся в спектрах кристаллов $\mathrm{LiNbO}_{3}: \mathrm{Zn}(0.004-2.00 \mathrm{~mol} . \% \mathrm{ZnO})$.

При концентрациях выше $1.42 \mathrm{~mol} \% \mathrm{ZnO}$ в исследованных кристаллах $\mathrm{LiNbO}_{3}: \mathrm{Zn}$ происходит тушение люминесценции от всех центров свечения (рис. 1). При этом в спектрах серии кристаллов $\mathrm{LiNbO}_{3}(0.004-2.00 \mathrm{~mol} \% \mathrm{ZnO})$ не возникает дополнительных полос излучения, связанных с дефектами, обусловленными наличием примесных ионов $\mathrm{Zn}^{2+}$ в структуре кристалла (таблица). Этот факт можно объяснить особенностями механизма вхождения ионов $\mathrm{Zn}^{2+}$ в структуру кристалла $\mathrm{LiNbO}_{3}$. Как известно, с повышением концентрации до первого концентрационного порога (3 mol.\% $\mathrm{ZnO})$ ионы $\mathrm{Zn}^{2+}$ преимущественно и плавно вытесняют точечные дефекты $\mathrm{Nb}_{\mathrm{Li}}$ [5]. При этом уменышается количество акцепторных точечных дефектов $\mathrm{V}_{\mathrm{Li}}$ и $\mathrm{V}_{\mathrm{Nb}}$ и происходит разрушение биполяронных пар $\mathrm{Nb}_{\mathrm{Nb}}-\mathrm{Nb}_{\mathrm{Li}}$ вплоть до концентрации $2.00 \mathrm{~mol} \% \mathrm{ZnO}$. Из рис. 2 видно, что увеличение концентрации ионов $\mathrm{Zn}^{2+}$ в кристалле приводит к уменьшению интенсивности полос люминесценции с максимумами при 2.50, 2.26 и $1.99 \mathrm{eV}$. Путем экстраполяции данных полос излучения получаем, что полное отсутствие центров свечения, обусловленных дефектами $\mathrm{V}_{\mathrm{Li}}, \mathrm{Nb}_{\mathrm{Nb}}$, $\mathrm{Nb}_{\mathrm{Nb}}-\mathrm{Nb}_{\mathrm{Li}}$, должно соответственно наблюдаться при концентрациях 6.32, 4.28 и 3.79 mol.\% ZnO. Расчеты хорошо согласуются с пороговыми значениями $(\approx 3.0$ и $\approx 7.0 \mathrm{~mol} . \% \mathrm{ZnO}$ ) концентраций ионов $\mathrm{Zn}^{2+}$ в кристалле $\mathrm{LiNbO}_{3}$. Так, полное вытеснение точечных дефектов $\mathrm{Nb}_{\mathrm{Li}}$ в кристаллах $\mathrm{LiNbO}_{3}: \mathrm{Zn}$ наблюдается при концентрации $\approx 5 \mathrm{~mol} . \% \mathrm{ZnO}$, а исчезновение точечных дефектов $\mathrm{V}_{\mathrm{Li}}$ - при концентрации $\approx 7.00 \mathrm{~mol} . \% \mathrm{ZnO}[5,19]$.

При малых концентрациях „нефоторефрактивные“ катионы $\mathrm{Zn}^{2+}, \mathrm{Mg}^{2+}$ и др. способны в структуре кристалла $\mathrm{LiNbO}_{3}$ образовывать мелкие электронные ловушки вблизи дна зоны проводимости, названные в работе [20] „уровнями прилипания“. Уместно отметить, что эффекты влияния ионов $\mathrm{Zn}^{2+}$ и $\mathrm{Mg}^{2+}$ на оптические свойства кристалла $\mathrm{LiNbO}_{3}$ очень похожи, что можно объяснить их схожим влиянием на состояние дефектной структуры кристалла [5]. Так, ион $\mathrm{Mg}^{2+}$ образует „комплекс $\mathrm{Mg}^{+4}$, который представляет собой ион $\mathrm{Mg}^{+}$с делокализованным на ряде окружающих ионов электроном, находящийся в позиции иона $\mathrm{Li}^{+}$ идеальной стехиометрической структуры $[3,5]$. При этом заметно снижается эффект фоторефракции вследствие повышения эффективной излучательной рекомбинации фотовозбужденных электронов, без их захвата глубокими электронными ловушками типа дефектов $\mathrm{Nb}_{\mathrm{Li}}$ или ионов $\mathrm{Fe}^{3+}$. В работе [21] с использованием метода функционала плотности (DFT-метод) выполнены расчеты электронной структуры гексагональной суперячейки, состоящей из 120 атомов, кристалла $\mathrm{LiNbO}_{3}$, легированного магнием. Результаты работы [21] показали, что с увеличением в кристалле концентрации ионов $\mathrm{Mg}^{2+}$ с 0.83 до 3.33 atom.\% (с 4.16 до 16.6 mol.\%) локальные уровни магния образуются преимущественно около дна зоны проводимости без образования глубоких уровней энергий в запрещенной зоне кристалла $\mathrm{LiNbO}_{3}$. По аналогии можно предположить, что локальные уровни энергии, обусловленные наличием точечного дефекта $\mathrm{Zn}_{\mathrm{Li}}$, также должны образовываться вблизи дна зоны проводимости в виде мелких донорных уровней энергии в запрещенной зоне, поскольку механизмы вхождения малых количеств ионов $\mathrm{Zn}^{2+}$ и $\mathrm{Mg}^{2+}$ в структуру кристалла $\mathrm{LiNbO}_{3}$ одинаковы. А именно, малые количества ионов $\mathrm{Zn}^{2+}$ и $\mathrm{Mg}^{2+}$ локализуются в структуре в позициях ионов $\mathrm{Li}^{+}$идеальной стехиометрической структуры, образуя точечные дефекты $\mathrm{Zn}_{\mathrm{Li}}, \mathrm{Mg}_{\mathrm{Li}}[5,22]$. При этом происходит повышение упорядочения катионной подрешетки, и поляризуемость кислородных кластеров $\mathrm{MeO}_{6}$ $(\mathrm{Me}=\mathrm{Zn}, \mathrm{Mg})$ изменяется так, что форма октаэдров $\mathrm{O}_{6}$ становится более правильной, более приближенной к форме октаэдров $\mathrm{O}_{6}$ стехиометрического кристалла [23]. Необходимо отметить, что в идеальном стехиометрическом кристалле (для которого $R=\mathrm{Li} / \mathrm{Nb}=1$ и в котором отсутствуют точечные дефекты в виде рядом стоящих одноименных катионов и вакансий) нет активных центров свечения. По этой причине в реальных стехиометрических кристаллах интенсивность спектра люминесценции должна быть малой, что и подтверждается данными работы [17]. Кроме того, из рис. 1, $a$ видно, что с повышением концентрации [ $\mathrm{ZnO}]$ до $2.00 \mathrm{~mol} \%$ излучение происходит с одних и тех же уровней энергии, что также подтверждает наличие мелких уровней, образованных атомами $\mathrm{Zn}_{\mathrm{Li}}$, у дна зоны проводимости.

На рис. $1, b$ представлены спектры фотолюминесценции конгруэнтного кристалла $\mathrm{LiNbO}_{3}$ и серии кристаллов $\mathrm{LiNbO}_{3}: \mathrm{Zn} \quad(4.46-6.50 \mathrm{~mol} \% \mathrm{ZnO})$. В отличие от спектров фотолюминесценции кристаллов $\mathrm{LiNbO}_{3}$, легированных $\mathrm{Zn}$ с концентрацией меньше первого порогового значения (рис. 1,a), наблюдается сложное люминесцентное гало, состоящее в основном из двух широких полос излучения с главным максимумом при $\approx 2.50$ и побочным максимумом при $\approx 1.90 \mathrm{eV}$. Размытое люминесцентное гало смещается в высокоэнергетическую область спектра при концентрациях $[\mathrm{ZnO}] \geq 4.46 \mathrm{~mol} \%$ п примерно на $\Delta E=0.41 \mathrm{eV}$ относительно главного максимума в конгруэнтном $\mathrm{LiNbO}_{3}$. Смещение можно связать с двумя факторами: изменением края фундаментального поглощения кристаллов $\mathrm{LiNbO}_{3}: \mathrm{Zn}(4.46-6.50 \mathrm{~mol} . \% \mathrm{ZnO})$ и образованием новых каналов рекомбинации с участием „новых/старых“ центров свечения. Причем изменение 
ширины запрещенной зоны $(\Delta E= \pm 0.1 \mathrm{eV})$ практически не меняется от концентрации $\mathrm{Zn}$ в диапазоне $5.00-9.00 \mathrm{~mol} . \%$ и наибольшее смещение $(\Delta E=0.30 \mathrm{eV})$ наблюдается для образцов конгруэнтного $\mathrm{LiNbO}_{3}$ и $\mathrm{LiNbO}_{3}: \mathrm{Zn}(9.0 \mathrm{~mol} \% \mathrm{ZnO})$ [24]. Из рис. $1, b$ видно, что от образца к образцу гало смещается незначительно и немонотонно в зеленой области спектра, кроме спектра кристалла $\mathrm{LiNbO}_{3}: \mathrm{Zn}(4.6 \mathrm{~mol} \% \% \mathrm{ZnO})$, где максимальная интенсивность свечения распределена в области от 1.91 до $2.48 \mathrm{eV}$. Изменения в спектрах люминесценции с приближением концентрации цинка ко второму концентрационному порогу могут быть обусловлены существенным изменением дефектного состояния кристаллов, т.е. появлением новых центров свечения, при вхождении катионов $\mathrm{Zn}^{2+}$ в диапазоне концентраций 4.46-6.50 mol.\%. Разделение контуров спектральных линий показывает, что интенсивность полосы люминесценции с максимумом при $2.50 \mathrm{eV}$ мала (рис. 2, таблица) в спектрах сильно легированных кристаллов, что свидетельствует о практически полном отсутствии в них вакантных позиции лития. В то же время вакантные позиции лития частично занимают атомы ниобия и атомы цинка, излучение которых уверенно присутствует при 2.26 и $2.66 \mathrm{eV}$. Кроме того, присутствует незначительное количество центров свечения, связанных с вакансиями по ниобию при $3.19 \mathrm{eV}$. Результаты, полученные нами, хорошо согласуются с результатами, полученными в работе [25] для серии кристаллов $\mathrm{LiNbO}_{3}: \mathrm{Zn}(3.43-5.84 \mathrm{~mol} \% \mathrm{ZnO})$ методом рентгеноструктурного анализа. В работе [25] было показано, что в образцах $\mathrm{LiNbO}_{3}: \mathrm{Zn}$ в области высоких концентраций цинка дефектность кристаллов описывается следующей моделью: все вакантные позиции лития заняты, во всех образцах стабильно наблюдаются дефекты $\mathrm{Nb}_{\mathrm{Li}}$, атомы цинка также занимают вакантные позиции лития, а также наблюдаются вакантные позиции ниобия.

Как видно из рис. 2, в кристаллах $\mathrm{LiNbO}_{3}: \mathrm{Zn}(4.46-6.5 \mathrm{~mol} \% \mathrm{ZnO})$ доминирует свечение, обусловленное дефектами $\mathrm{Nb}_{\mathrm{Li}}$. Возможны две причины для объяснения этого факта. Во-первых, это может быть обусловлено наличием других центров свечения, которые участвуют в процессе переноса возбужденной энергии совместно с дефектами $\mathrm{Nb}_{\mathrm{Li}}$, которые являются глубокими электронными ловушками. Подтверждением тому является доминирующая полоса излучения при $2.26 \mathrm{eV}$ (таблица), интенсивность которой растет с увеличением концентрации Zn в кристалле. Стоит отметить, что излучательная рекомбинация центров свечения (вакансий и междоузельных атомов как кислорода, так и цинка) индивидуального соединения $\mathrm{ZnO}$ преобладает в зеленой области спектра [26]. Возможно, образуется парный (комплексный) дефект при внедрении атомов Zn в структуру кристаллической решетки $\mathrm{LiNbO}_{3}$. Кроме того, интенсивность дополнительного максимума при $2.66 \mathrm{eV}$ увеличивается с увеличением концентрации Zn. Во-вторых, в кристаллах $\mathrm{LiNbO}_{3}: \mathrm{Zn}(4.46-6.5$ mol.\% $\mathrm{ZnO})$ всетаки присутствуют дефекты $\mathrm{Nb}_{\mathrm{Li}}$. При этом сохранение электронейтральности можно объяснить в рамках модели ниобиевых вакансий [2]. Феноменологичность второго случая указывает на разные механизмы компенсации заряда при легировании кристаллов $\mathrm{LiNbO}_{3}$ катионами цинка в слабо и в сильно легированных кристаллах. На эти механизмы могут также влиять особенности технологий шихты и кристаллов. Полученные нами данные подтверждают это. На рис. $1, b$ (кривая 4) в спектре кристалла $\mathrm{LiNbO}_{3}: \mathrm{Zn}$ (4.69 mol.\% ZnO), выращенного из шихты, синтезированной с использованием прекурсора $\mathrm{Nb}_{2} \mathrm{O}_{5}: \mathrm{Zn}$ (технология гомогенного легирования), наблюдается равномерное распределение интенсивности свечения от разных центров с преобладанием свечения в длинноволновой области спектра. В то же время спектры остальных кристаллов $\mathrm{LiNbO}_{3}: \mathrm{Zn}$, полученных методом прямого легирования расплава, таких особенностей не имеют. Таким образом, кристалл $\mathrm{LiNbO}_{3}: \mathrm{Zn}(4.69 \mathrm{~mol} \%$ $\mathrm{ZnO})$, полученный по технологии гомогенного легирования, обладает большим количеством дефектных центров, чем другие исследованные кристаллы $\mathrm{LiNbO}_{3}: \mathrm{Zn}$, выращенные путем непосредственного введения оксида цинка в шихту ниобата лития перед наплавлением тигля.

Из рис. 2 видно, что в $\mathrm{LiNbO}_{3}: \mathrm{Zn}(4.52 \mathrm{~mol} . \% \mathrm{ZnO})$ наблюдается резкое падение интенсивности полос излучения при $3.19,2.66,2.50$ и $1.99 \mathrm{eV}$. Такая особенность может указывать на тушение излучательной рекомбинации за счет сильного электрон-фононного взаимодействия между центрами захвата и атомами в узлах кристаллической решетки, т. е. должны появляться множественные безызлучательные переходы. Так, в работе [7] в спектрах КРС кристаллов $\mathrm{LiNbO}_{3}: \mathrm{Zn}$ при легировании расплава $[\mathrm{ZnO}]=5.38-6.76 \mathrm{~mol} \%$ ш ширина спектральных полос, обусловленных колебаниями катионов $\left(200-300 \mathrm{~cm}^{-1}\right)$, находящихся в кислородных октаэдрах $\mathrm{MeO}_{6}$, и колебаниями кислородных октаэдров (500-900 $\left.\mathrm{cm}^{-1}\right)$, увеличивается, что указывает на анизотропное расширение кислородных октаэдров преимущественно вдоль полярной оси за счет внедрения атомов $\mathrm{Zn}$ в позиции основных катионов металлов (Nb, Li). Кроме того, данные по фотоиндуцированному рассеянию света (ФИРС) [7] показывают, что в образце $\mathrm{LiNbO}_{3}: \mathrm{Zn}$ (4.54 mol.\% ZnO) фоторефрактивный отклик отсутствует, и наблюдается почти идеальное круговое рассеяние на статических структурных дефектах.

\section{Заключение}

Исследованы концентрационные изменения в спектрах фотолюминесценции двух серий кристаллов $\mathrm{LiNbO}_{3} \quad(0.004-2.00 \mathrm{~mol} . \% \quad \mathrm{ZnO}) \quad$ и $\mathrm{LiNbO}_{3} \quad(4.46-6.50 \mathrm{~mol} . \% \quad \mathrm{ZnO}) . \quad$ Показано, что дефекты $\mathrm{Zn}_{\mathrm{Li}}$ создают мелкие уровни энергии 
у дна зоны проводимости. С приближением состава кристалла к первому $(\approx 3.0 \mathrm{~mol} . \% \mathrm{ZnO})$ концентрационному порогу наблюдается уменьшение интенсивности полос люминесценции с максимумами при 2.50, 2.26 и $1.99 \mathrm{eV}$, обусловленных дефектами $\mathrm{V}_{\mathrm{Li}}, \quad \mathrm{Nb}_{\mathrm{Li}}, \quad \mathrm{Nb}_{\mathrm{Nb}}-\mathrm{Nb}_{\mathrm{Li}} . \quad \mathrm{B}$ спектрах кристаллов $\mathrm{LiNbO}_{3}: \mathrm{Zn} \quad(4.46-6.5 \mathrm{~mol} \% \% \quad \mathrm{ZnO}) \quad$ обнаружено аномальное поведение интенсивности полос люминесценции с приближением их состава ко второму концентрационному порогу при $\approx 7.0 \mathrm{~mol} \% \mathrm{ZnO}$. А именно, происходит смещение люминесцентного гало на $\approx 0.41 \mathrm{eV}$ в высокоэнергетическую область спектра, и в кристалле увеличивается интенсивность центров свечения при 2.66 и $2.26 \mathrm{eV}$ с увеличением концентрации Zn. Показано, что это может быть обусловлено изменением механизма сохранения электронейтральности кристалла при высоких (близких ко второму концентрационному порогу) концентрациях ионов $\mathrm{Zn}^{2+}$ в нем. Показано, что в кристалле $\mathrm{LiNbO}_{3}: \mathrm{Zn}$ (4.69 mol.\% $\mathrm{ZnO}$ ), полученном по технологии гомогенного легирования, существует большее количество центров свечения разной природы, чем в конгруэнтном кристалле и в легированных цинком кристаллах, полученных по технологии прямого легирования расплава. В кристалле $\mathrm{LiNbO}_{3}: \mathrm{Zn}$

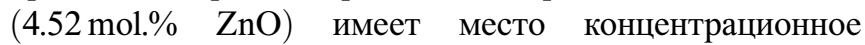
тушение люминесценции, обусловленной дефектами $\mathrm{V}_{\mathrm{Li}}, \mathrm{Nb}_{\mathrm{Nb}}, \mathrm{Zn}_{\mathrm{Li}}$, за счет сильного электрон-фононного взаимодействия между центрами свечения и атомами кристаллической решетки, что обусловливает его наилучшие фоторефрактивные свойства в серии кристаллов $\mathrm{LiNbO}_{3}: \mathrm{Zn}(4.46-6.50 \mathrm{~mol} . \% \mathrm{ZnO})$.

\section{Финансирование работы}

Исследования выполнены при частичной финансовой поддержке РФФИ в рамках научного проекта № 20-3390078.

\section{Конфликт интересов}

Авторы заявляют, что у них нет конфликта интересов.

\section{Список литературы}

[1] Abrahams S.C. Properties of Lithium Niobate. NY., 1989. $234 \mathrm{p}$.

[2] Abrahams S.C., Marsh P. // Acta. Cryst. 1986. V. B42. P. 61. doi 10.1107/S0108768186098567

[3] Wong K.K. Properties of Lithium Niobate. INSPEC-The institution of Electrical Engineers. London, UK, 2002. 143 p.

[4] Prokhorov A.M., Kuz'minov Yu.S. Physics and Chemistry of Crystalline Lithium Niobate. NY: Adam Hilger, 1990. 237 p.

[5] Сидоров Н.В., Волк Т.Р., Маврин Б.Н., Калинников В.Т. Ниобат лития: дефекты, фоторефракция, колебательный спектр, поляритоны. М.: Наука, 2003. 255 с.
[6] Volk T., Wohlecke M. Lithium Niobate. Defects, Photorefraction, and Ferroelectric Switching. Berlin: Springer, 2008. $250 \mathrm{p}$.

[7] Палатников М.Н., Сидоров Н.В., Макарова О.В., Бирюкова И.В. Фундаментальные аспекты технологии сильно легированных кристаллов ниобата лития. Апатиты: КНЦ PAH, 2017. $241 \mathrm{c}$.

[8] Kemlin V., Jegouso D., Debray J., Boursier E., Segonds P., Boulanger B., Ishizuki H., Taira T., Mennerat G., Melkonian J.-M., Godard A. // Opt. Express. 2013. V. 21. N 23. P. 28886. doi 10.1364/OE.21.028886

[9] Shur V.Ya, Akhmatkhanov A.R., Baturin I.S. // Appl. Phys. Rew. 2015. V. 2. P. 040604-1. doi 10.1063/1.4928591

[10] Палатников М.Н., Сидоров Н.В., Бирюкова И.В., Щербина О.Б., Калинников В.T. // Перспективные материалы. 2011. № 2. C. 93.

[11] Сидоров Н.В., Яничев А.А., Палатников М.Н., Габаин А.A. // Опт. и спектр. 2014. Т. 116. № 2. С. 306; Sidorov N.V., Yanichev A.A., Palatnikov M.N., Gabain A.A. // Opt. Spectrosc. 2014. V. 116. N 2. P. 281.

[12] Emond M.H.J., Wiegel M., Blasse G., Feigelson R. // Mat. Res. Bull. 1993. V. 28. P. 1025. doi 10.1016/0025-5408(93)90140-9

[13] Krol D.M., Blasse G., Powell R.C. // J. Chem. Phys. 1980. V. 73(1). P. 163. doi 10.1063/1.439901

[14] Fischer C., Wöhlecke M., Volk T., Rubinina N. // Phys. Stat. Sol. (a). 1993. V. 137. P. 247. doi 10.1002/pssa.2211370122

[15] Ахмадуллин И.Ш., Голенищев-Кутузов В.А., Мигачев С.A. // ФТТ. 1998. Т. 40. № 6. С. 1109.

[16] Яковлев В.Ю., Кабанова Е.В., Вебер Т., Пауфлер П. // ФTT. 2001. T. 43. № 8. C. 1520.

[17] Смирнов М.В., Сидоров Н.В., Палатников М.Н., Пикулев В.Б. // Труды Кольского научного центра. 2019. Т. 10. № 3. C. 323.

[18] Voloshyna O., Boiaryntseva I., Spassky D., Sidletski O. // Solid State Phenomena. 2015. V. 230. P. 172. doi 10.4028/www.scientific.net/SSP.230.172

[19] Glass A.M., Peterson G.E., Negran T.J. // Laser Induced Damage in Opt. Materials. NBS Spec. Publ. 1972. N 372. P. 15.

[20] Блистанов А.А., Любченко В.М., Горюнова А.Н. // Кристаллография. 1998. Т. 43. № 1. С. 86.

[21] Yanl Li, Lili Li, Xiufeng Cheng, Xian Zhao. // J. Phys. Chem. C. 2017. V. 121. P. 8969. doi 10.1021/acs.jpcc.7b01274

[22] Donnerberg H.J., Tomlinson S.M., Catlow C.R.A. // J. Phys. Chem. Solids. 1991. V. 52. N 1. P. 201. doi 10.1016/0022-3697(91)90065-8

[23] Сидоров Н.В., Яничев А.А., Палатников М.Н., Габаин А.А., Пикуль О.Ю. // Опт. и спектр. 2014. Т. 117. № 1. C. 76; Sidorov N.V., Yanichev A.A., Palatnikov M.N., Gabain A.A., Pikoul O.Y. // Opt. Spectrosc. 2014. V. 117. N 1. P. 72.

[24] Castillo-Torres J. // Opt. Commun. 2013. V. 290. P. 107.

[25] Кадетова А.В. Влияние легирования на структурные особенности ниобата лития. Автореф. дис. магистра по направлению „Электроника и наноэлектроника“. Петрозаводск: ПетрГУ, 2018.

[26] Cheol Hyoun Ahn, Young Yi Kim, Dong Chan Kim, Sanjay Kumar Mohanta, Hyung Koun Cho // J. Appl. Phys. 2009. V. 105. P. 013502-1. 